\title{
Motivational Patterns Of Enrollees In University-Based Executive And Professional Education Courses
}

Vincent S. Daniels, Nova Southeastern University, USA

Robert C. Preziosi, Nova Southeastern University, USA

\begin{abstract}
The purpose of this paper is to begin an exploration into high-skills lifelong learning in the field of business and management, referred to as executive and professional education (EPE). Several additional undertakings were necessary, including: discovering methods of valuing knowledge to a region, state or country, and establishing why participants in EPE programs enroll in them. To support this inquiry two research questions were developed, as follows: 1 . What are the components of relevant EPE? 2. What motivates participants to take part in EPE? An exploratory case study was written exploring the intricacies of developing a successful EPE department. This exploratory case study served as a basis for developing a survey, administered to participants in EPE to determine reasons for their participation. This final survey was conducted in the classroom. The researchers believe that the findings and conclusions will be of value to practitioners involved in EPE, as well as to academics studying this area of business education. This research exercise has assisted the researchers in being more effective in managing and developing EPE within their own university. As professions and skills are made obsolete in the knowledge economy the need for continued high level lifelong learning becomes increasing important to the sustainability and viability of local, regional, state and national economies.
\end{abstract}

Keywords: Adult Education, Executive Education, Non-credit Courses, Student Motivation.

\section{INTRODUCTION AND RESEARCH QUESTIONS}

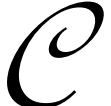

urrent economic thinking in developed western countries places knowledge led industries in the forefront of economic development (Gore, 1999). Taking this concept as a starting point, the paper will seek to examine to what extent the presence of an active education system is required to support the growth of knowledge led economic development at state level. To evaluate the concept that education underpins the development of local knowledge led industries (Drucker, 1999; OECD, 1999; Wood, 2003), a target system is required.

\section{Executive and professional education}

The leadership and management roles of the future require additional and continually evolving skills and knowledge. EPE consists of two primary areas; professional technical knowledge and "soft skills". The focus of this paper is "soft skills". These are skills such as leadership and communication that are essential to success. With a constant evolution of new jobs in the knowledge based economy (Kerka, 1993) leaders and professionals are required to be continually updating and refining these essential skills. Soft skill development is especially important to technical workers in areas such as engineering and project management (Nyman, 2006; Singh, 2005) because they have to be able to work within an organization and influence others at different levels. 


\section{Entering the information age}

During the industrial era the use of knowledge was evident. Many knowledge workers were considered service workers: "By 1953, more than 50\% of the American labor force was working in the service sector of the economy, more than in farming and manufacturing combined" (Brown, 2002).

As a result of the recognition that productivity is key, two major adjustments had to be made to the existing methods used to measure a nation's wealth. First, we began to gauge the Gross National Product, which acknowledges that the knowledge base of a country must be considered in order to ascertain true national wealth. In fact, some believe that the traditional categorization (wealth is determined by land, labor and capital) has been surpassed by knowledge as the prime resource (Anell, 2002). In the developed free-market countries today, less than five percent of the population is involved in agriculture (Drucker, 1994). A second adjustment in the knowledge-based economy is the value of education. Workers in an industrial-based economy require only a basic education and complete high school or trade school with enough preparation for the rest of their lives, with the possible exception of learning a particular function in a factory. The move to an information age requires higher skills, even for factory work, and the knowledge manager or professional requires higher levels of learning (Brown et al., 2001).

According to Grant (Chauvel and Despres 2000, p27), if knowledge exists in two principal forms, explicit and tacit, and at two major levels, the individual and the organization then there are significant benefits to the organization in shifting its primary knowledge base from individually held tacit knowledge to organization-wide explicit knowledge.

The critical difference between tacit and explicit knowledge relates to how easy or difficult it is to codify or express the knowledge in terms which enable it to be understood by a broad audience. If knowledge can be codified in this way then it can made explicit and thus readily transferable (Burton-Jones, 2001).

\section{Explicit knowledge critical to EPE}

This transformation of tacit to explicit knowledge through the development of a relevant body of knowledge facilitates the teaching and learning process in EPE. It is often fiscally impossible to work one-on-one with every practitioner in a particular field in order to allow the participant to develop skills through experiential learning alone. By making tacit knowledge available in an explicit form the participant can learn and then apply, hence speeding the development of mastery of the field of study.

Nonaka (1994) proclaimed four modes of knowledge conversion. He argued the assumption that knowledge is created through conversion between tacit and explicit knowledge allows us to postulate four different modes of knowledge conversion:

(1) Socialization - from tacit knowledge to tacit knowledge.

(2) Combination - from explicit knowledge to explicit knowledge.

(3) Externalization - from tacit knowledge to explicit knowledge.

(4) Internalization - from explicit knowledge to tacit knowledge.

Knowledge of itself is valuable but in order to have economic value it must be used and be able to increase the competitive advantage of the organization (Nonaka \& Takeuchi, 1995). Universities by virtue of their role in generation, dissemination and validation of knowledge are able to make significant contributions to the knowledge and skills of local industry thus increasing the knowledge value of an area.

To understand the value that a continuing EPE, delivered through universities and colleges requires an understanding of how knowledge is valued. Measuring, on a national or regional level, the efficacy of the implementation and development of an internal, knowledge-based economy is a new concept in economics (OECD, 1996). 


\section{Intellectual capital: human, structural and client capital}

Intellectual Capital (IC) is a measurement of all intangible resources, including knowledge. Klein (1998, p. 1) defines IC as "knowledge, experiences, expertise, and associated soft assets, rather than their hard physical and financial capital". In this era of the knowledge-based economy, IC becomes a most valuable asset in an organizations overall value and competitive advantage (Moon \& Kym, 2006).

IC includes human and structural capital, both of which have knowledge components. When an organization captures knowledge and then codifies it, converting the knowledge from tacit to explicit, making the knowledge easily transferable, this knowledge is considered to be structural capital of the organization (Stewart, 1997).

\section{Human capital}

The human capital portion of IC consists of the intangible resources of the members of the organization. This includes: competencies (skills and know-how); attitude; creativity, capability for innovation, and intellectual agility. While recognition of IC is of great value to an organization, assigning consistent metrics to the components of IC is nearly impossible, to the chagrin of accountants and financial analysts. Traditional accounting becomes inadequate when a firms value is primarily in intangible assets. The market value of knowledge intensive companies can far exceed the value placed on tangible assets listed in a financial statement.

\section{Need for continuing education}

In the information and knowledge-based world the need for a continuing education is obvious. A continually increasing number of workers will, in addition to changing jobs a record number of times, also move from one career to another as some careers become obsolete and new ones emerge (Kerka, 1993). It is unlikely that traditional colleges and universities, which tend to teach broad knowledge areas rather than specific skills, will meet the demand for continuing education. According to Garnett, "In the age of the 'knowledge driven economy' and the 'corporate university' the creation and evaluation of knowledge is now recognized as too important and pervasive to be left to higher education" (Garnett, 2001, p. 78).

\section{High skills in the knowledge economy}

Although learning takes place throughout the life of a person, higher knowledge and skills are typically gained during the course of higher education, which usually takes place in universities and colleges, technical schools and organizational training programs. Higher education includes traditional degree programs as well as continuing lifelong education and learning. The area of particular interest to this paper is continuing adult education in fields relevant to dispersing advanced knowledge and high skills in the area of business.

High-skills EPE consists of educational and learning programs offered to management level employees and above. In the areas of skills in the EPE definition are programs for managers, executives and professionals. These may be courses targeted towards officers and managers in business corporations, not-for-profit organizations and government bodies. Also included in this definition are professionals operating in the high-skills arena, requiring advanced education and, in most cases, professional certification. This group includes such professions as lawyer, accountant, physician and educator. In most cases activity in these professions requires continuing education relative to the profession, but may include business and management education.

\section{Functional skills}

EPE falls into two categories. The first category might be called "functional" education. Functional programs are those which are primarily concerned with knowledge rather than skills. These may cover functional areas that are typically covered in a Master of Business Administration (MBA) or other management program such as Master of Public Administration (MPA) or Master of Science program in specialized business topics such as finance or marketing. 


\section{Soft skills}

The second EPE category might be called the "social-behavioral skills" area. These programs are generally related to so-called soft-skills development. These skill areas might address communication or leadership skills. While knowledge is required for these skills to be developed, the primarily goal of these programs is to assist participants in developing skills that they can bring back to the workplace. These skills will hopefully make them better managers.

\section{Why do people participate in EPE type education?}

Participants take part in EPE for a variety of reasons. A survey was conducted by the Hudson Institute of Entrepreneurship and Executive Education of Nova Southeastern University to determine the reasons for participation. The results of this survey are included in Appendix A.

The primary reasons for participation are:

- $\quad$ To increase skills or knowledge in a current career or profession

- To prepare for transition to a different career or profession

- $\quad$ To move into a position of management or leadership

- To advance to a higher level management or leadership position

- $\quad$ To be recognized as an expert in a career or profession

\section{Role of business schools}

The schools and colleges of business within the universities have found a niche in higher levels of continuing business education. While the community colleges concentrate on basic skills, the universities concentrate more on high skills involved with EPE. These skills are typically in advanced concepts of finance, management, leadership and business technology. This paper will focus on the concept of executive education, which is education that prepares managers and executives for higher levels of responsibility in the organization (Crotty \& Soule, 1997). Included in this educational category will be management and executive education and professional education advancing specific skills for high-skills workers and managers. While management and executive education is more general in scope and may include advanced concepts in finance, management, leadership and business technology, professional education is more directed at preparing professionals in a very specific area, such as project management, treasury management, management accounting, human resource management, training and development, or purchasing management. Frequently, professional education leads to a particular certification from a recognized certifying agency.

\section{RESEARCH METHOD}

Education is central to many policy decisions relating to economics and social development. Addressing this issue - how can education systems contribute to development of local knowledge economies - is a central theme of the research reported in this paper. It is acknowledged that the study of the whole range of educational provision would be impractical.

During the period of the research the researchers were employed at Florida International University (FIU) in Miami and Nova Southeastern University, a private not-for-profit university located in Fort Lauderdale. In both instances, the researchers were involved in business and management education for practicing professionals. Based on experience gained from these employments the impact of education on knowledge skills of professionals and the building of that capability and capacity is thought to be necessary for companies to develop competitive advantage and hence a knowledge led local economy.

\section{Research Questions}

The following questions require investigation: 
1. What are the components of relevant EPE?

2. What motivates participants to take part in EPE?

Investigation of these questions will require a selection of techniques to collect data appropriate to each question. Thus, for example to investigate the motivation of participants in EPE the researcher may use questionnaires, interviews or a combination leading to data that is both numeric (questionnaire) and textual (interviews).

\section{Survey utilizing questionnaire}

With the cooperation of the Hudson Institute of Entrepreneurship and Executive Education (HIEEE) the researchers conducted a survey. The framework derived from the initial case study was used to establish numerous questions in the survey. The primary purpose of the survey is to address the question "What motivates participants to take part in EPE? 'In addition, survey elements will be utilized to substantiate proposed indicators developed by the authors.

Please rank the following statements as to their influence in motivating you to take part in this continuing education program.

1. Increase skills and knowledge in my current career/profession

2. Prepare for transition to a different career/profession

3. Enhance skills and knowledge to advance in current career/profession

4. Move into a management/leadership position

5. Be recognized as an expert in my current career/profession

Participants were asked to rate each of these on a scale of 0 through 5, as follows:

0. $\quad$ Not applicable

1. Not important in motivating me to take part in this program

2. Low importance, but somewhat affected my decision to enroll in this program

3. Important. This knowledge, or these skills are important to my future success

4. Very important. Not having these skills or this knowledge will be detrimental to my career development.

5. Highest importance. Absolutely essential for continued success.

As with any questions developed by involved individuals a certain amount of subjectivity can influence the question selection. It is believed that the experience of the director, coupled with the faculty/instructor review has made the question selection as objective as possible.

A Likert scale was utilized in collecting and evaluating responses of the participants. A Likert scale utilizes a five, seven or nine point rating scale. Respondent's attitudes are measured from lowest (1) to highest (5). A possible selection of "Not applicable" ( 0 ) is also included to be utilized by the respondent when applicable (Berg, 1998; Rea \& Parker, 1997). The Likert scale was accepted by the researcher as an adequate method to evaluate participant's attitude towards importance of the motivations indicated in the questions. A Likert scale offers an acceptable method of measuring the relative importance of goals (Maurer \& Pierce, 1998). While the Likert scale has been challenged as having potential differences in understanding among cultures, for the purpose of this research, where respondents were reasonably homogeneous, it was determined by the researcher to be an acceptable measuring device (Lee, Jones, Mineyama \& Zhang, 2002). There were 99 research participants.

\section{Validity and bias}

Validity is the extent to which the research findings accurately represent what is happening in the situation being studied (Hussey \& Hussey, p. 57). Validity is thus a requirement for both quantitative and qualitative research. A practical way of achieving validity is to minimize the bias inherent in research. The sources of bias are the characteristics, attitudes, opinions and beliefs of the developer of the questionnaire as well as of the respondent, and the content and syntax of the questions. Every effort has been made by the researcher to minimize the effects of bias in the research contained in this paper. 
An element of triangulation was also utilized to reduce potential bias in the survey questions: investigator triangulation (Yin, 1994). This was achieved by involving several professors and instructors of EPE in reviewing the questionnaire and validating the questions.

\section{Increase skills}

As evidenced in figure 6.1 fully seventy-five percent of respondents were involved in EPE programs to increase skills and knowledge in a current career or profession. While twenty participants did not rank this item, or ranked it as not applicable, only two respondents rated this reason as of low importance.

In the rapidly changing and advancing world of management and business, skills and knowledge must be constantly improved in order to remain current and competitive. This high ranking for this question was expected based on the research presented earlier in this paper.

Figure 6.1 Increase skills

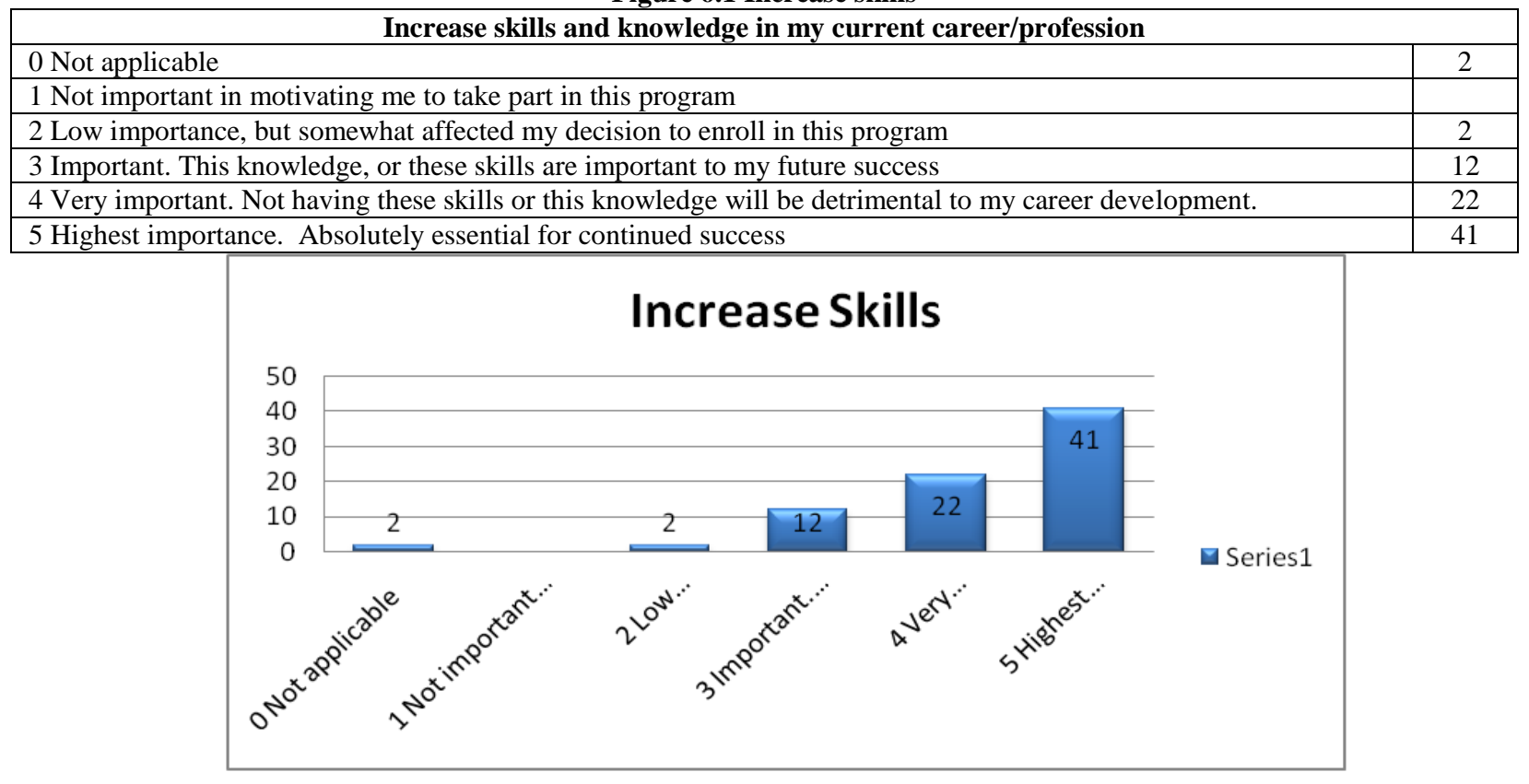

\section{Prepare for transition}

A somewhat surprising result was the response to the question relative to preparing for transition to a different career or position. As can be seen in figure 6.2 fully sixty percent of respondents ranked this reason as important or higher. Only forty percent ranked this reason for taking EPE programs as of low or no importance, or not applicable.

In view of the rapid changes in technology leading to unforeseen changes in productivity many careers and jobs are being outmoded and eliminated each year, as outlined earlier in this paper. It had been estimated that ten percent of job descriptions are disappearing at an annual rate. It appears from this research that participants are aware of this trend and want to prepare themselves in case their position or profession becomes superfluous.

Another possible reason for the preponderance of "important" responses to this question is that many participants are interested in changing to a new career path or profession for personal reasons. Further research must be conducted to determine what factors are involved in a high number of participants being interested in changing careers or professions. 
Figure 6.2 Transition

\begin{tabular}{|l|c|}
\multicolumn{2}{|c|}{ Prepare for transition to a different career/profession } \\
\hline 0 Not applicable & 21 \\
\hline 1 Not important in motivating me to take part in this program & 10 \\
\hline 2 Low importance, but somewhat affected my decision to enroll in this program & 8 \\
\hline 3 Important. This knowledge, or these skills are important to my future success & 19 \\
\hline 4 Very important. Not having these skills or this knowledge will be detrimental to my career development. & 16 \\
\hline 5 Highest importance. Absolutely essential for continued success & 25 \\
\hline
\end{tabular}

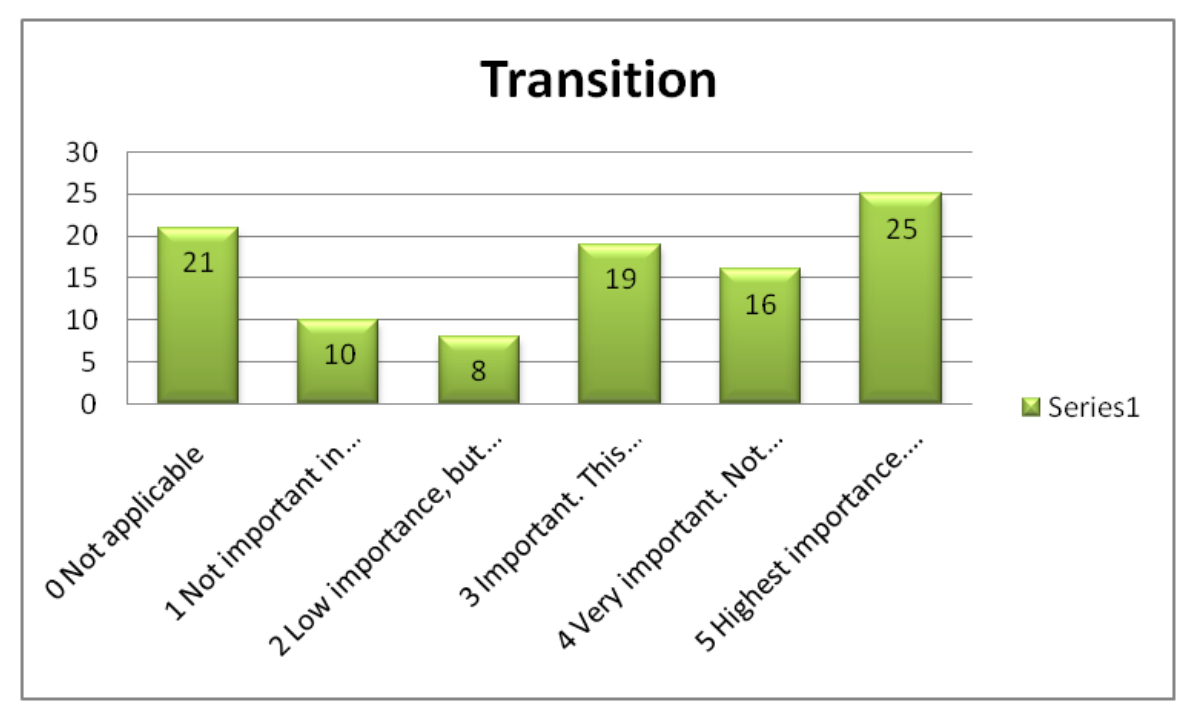

Table 6.3 Enhance skills

Enhance skills and knowledge to advance in current career/profession

\begin{tabular}{|l|c|}
\hline 0 Not applicable & 2 \\
\hline 1 Not important in motivating me to take part in this program & 2 \\
\hline 2 Low importance, but somewhat affected my decision to enroll in this program & 2 \\
\hline 3 Important. This knowledge, or these skills are important to my future success & 9 \\
\hline 4 Very important. Not having these skills or this knowledge will be detrimental to my career development. & 25 \\
\hline 5 Highest importance. Absolutely essential for continued success & 59 \\
\hline
\end{tabular}

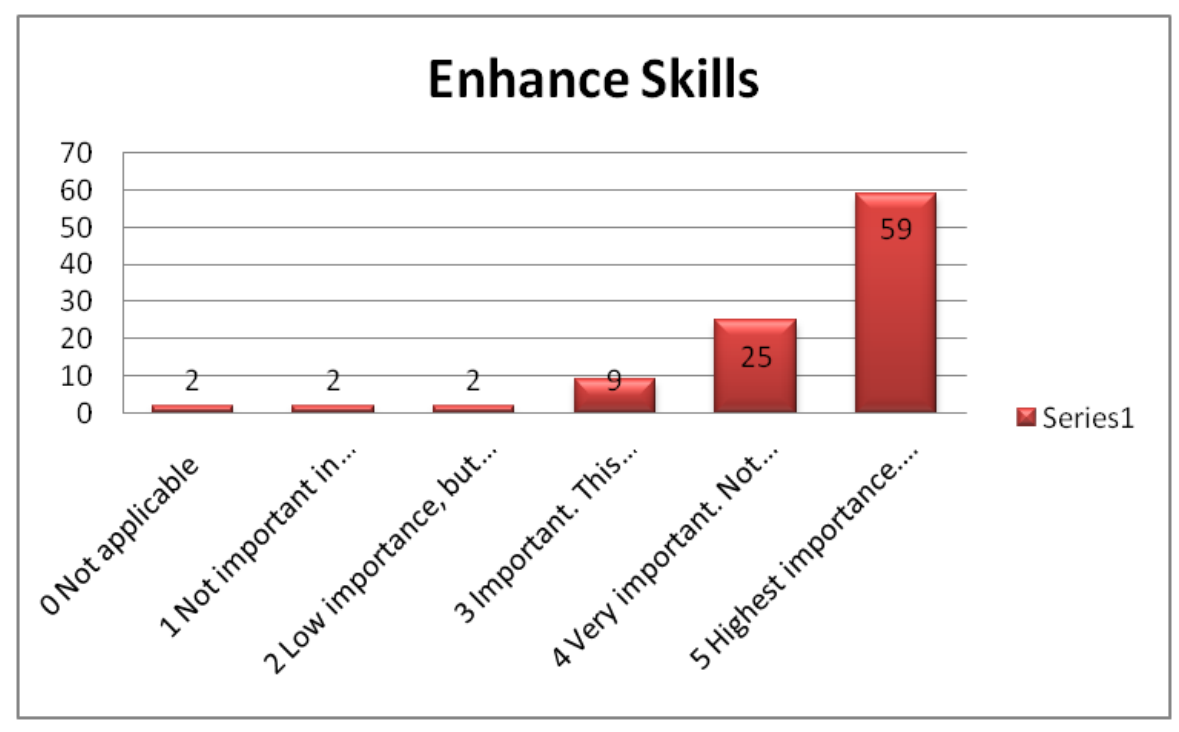




\section{Enhancing skills and knowledge}

Enhancing skills and knowledge to be able to advance in a current career or profession had the strongest positive response with ninety-three percent of the participants indicating that this reason was an important motivator. Fifty-nine percent of the participants ranked this reason as being of highest importance.

Lifelong learning has become an important part of the education delivered through universities, as universities are generally recognized as the repository of higher learning. These participants recognize the value of EPE in supplying the knowledge and skills required to advance.

\section{Move into management}

Twenty-four percent of the participants were not motivated, or had low motivation to take an EPE program to help them to move into management positions (Figure 6.4). While some of these respondents may have no desire to move into management or leadership it is more likely that a large percentage of these respondents are already in such a position. Further research is needed to determine the reasons why a significant percentage are not motivated to take EPE programs to move into management and leadership positions.

On the other hand, for seventy-five percent of respondents moving into a management or leadership position was important. Participants see the value of taking part in EPE programs in order to learn the skills necessary to advance into higher positions in the organization. The skills and knowledge necessary for being successful in a support role or a functional area are not the same skills that will make a person successful as a manager or leader. Also, having successfully completed a particular EPE program is a demonstration to organizational leaders of the participant's desire to move up as well as certification that he or she has learned necessary skills.

Figure 6.4 Move into management/leadership

\begin{tabular}{|l|c|}
\hline \multicolumn{1}{|c|}{ Move into a management/leadership position } & 15 \\
\hline 0 Not applicable & 6 \\
\hline 1 Not important in motivating me to take part in this program & 3 \\
\hline 2 Low importance, but somewhat affected my decision to enroll in this program & 16 \\
\hline 3 Important. This knowledge, or these skills are important to my future success & 20 \\
\hline 4 Very important. Not having these skills or this knowledge will be detrimental to my career development. & 39 \\
\hline 5 Highest importance. Absolutely essential for continued success & 39 \\
\hline
\end{tabular}

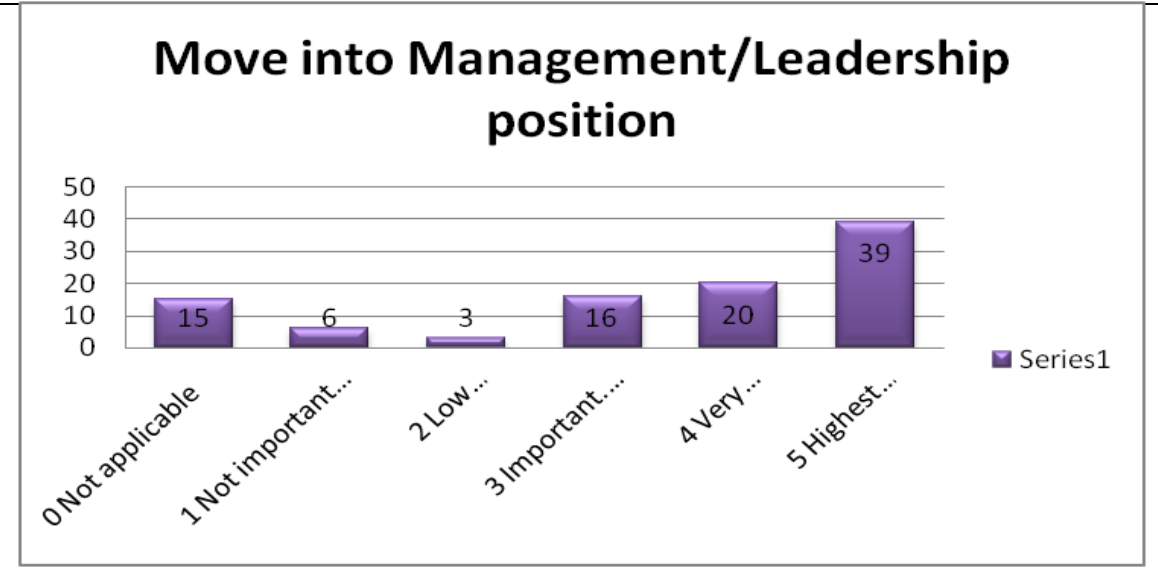

\section{Move to higher level}

Forty-one percent of participants ranked moving to a higher level management or leadership position as of highest importance. Fifty-eight participants felt that his was an important motivator to taking EPE programs. 
Figure 6.5 Move to higher level

\begin{tabular}{|l|c|}
\hline Move to a higher level management/leadership position & 11 \\
\hline 0 Not applicable & 5 \\
\hline 1 Not important in motivating me to take part in this program & 1 \\
\hline 2 Low importance, but somewhat affected my decision to enroll in this program & 17 \\
\hline 3 Important. This knowledge, or these skills are important to my future success & \\
\hline 4 Very important. Not having these skills or this knowledge will be detrimental to my career development. & 41 \\
\hline 5 Highest importance. Absolutely essential for continued success & \\
\hline
\end{tabular}

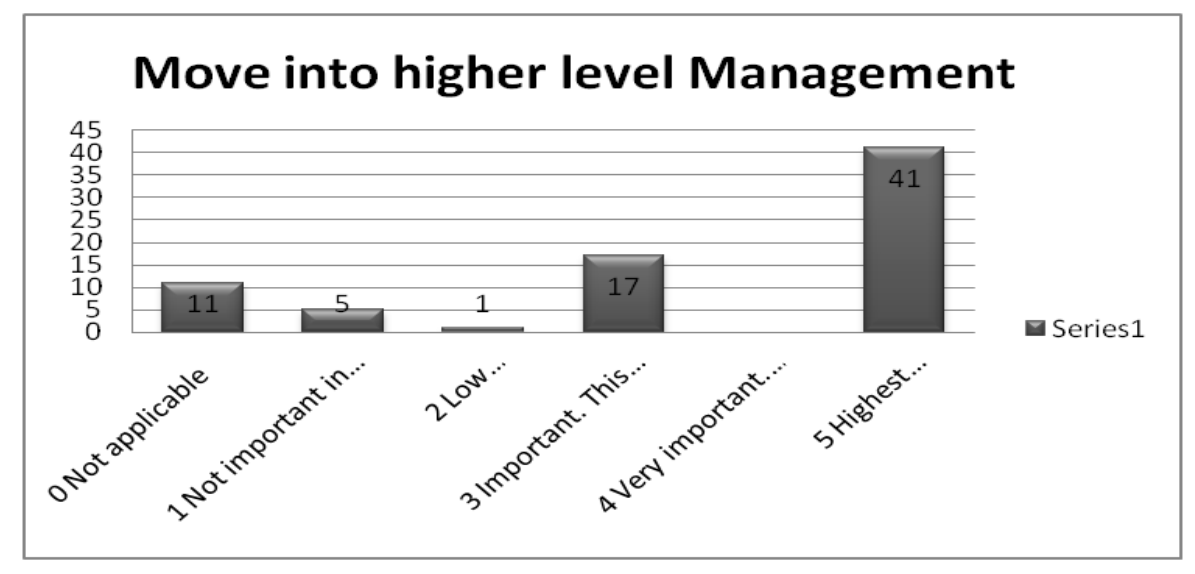

\section{Gain recognition}

Recognition was considered important or greater by eighty percent of participants. The HIEEE prints certificates of completion, suitable for framing for each participant in each program. The positive response to this question accentuates the desire for professional recognition.

These responses support the concepts presented in this paper about the importance of certification preparation programs as an integral part of the EPE offering.

Figure 6.6 Recognition

Be recognized as an expert in my current career/profession

\begin{tabular}{|l|c|}
\hline 0 Not applicable & 6 \\
\hline 1 Not important in motivating me to take part in this program & 6 \\
\hline 2 Low importance, but somewhat affected my decision to enroll in this program & 7 \\
\hline 3 Important. This knowledge, or these skills are important to my future success & 20 \\
\hline 4 Very important. Not having these skills or this knowledge will be detrimental to my career development. & 14 \\
\hline 5 Highest importance. Absolutely essential for continued success & 46 \\
\hline
\end{tabular}

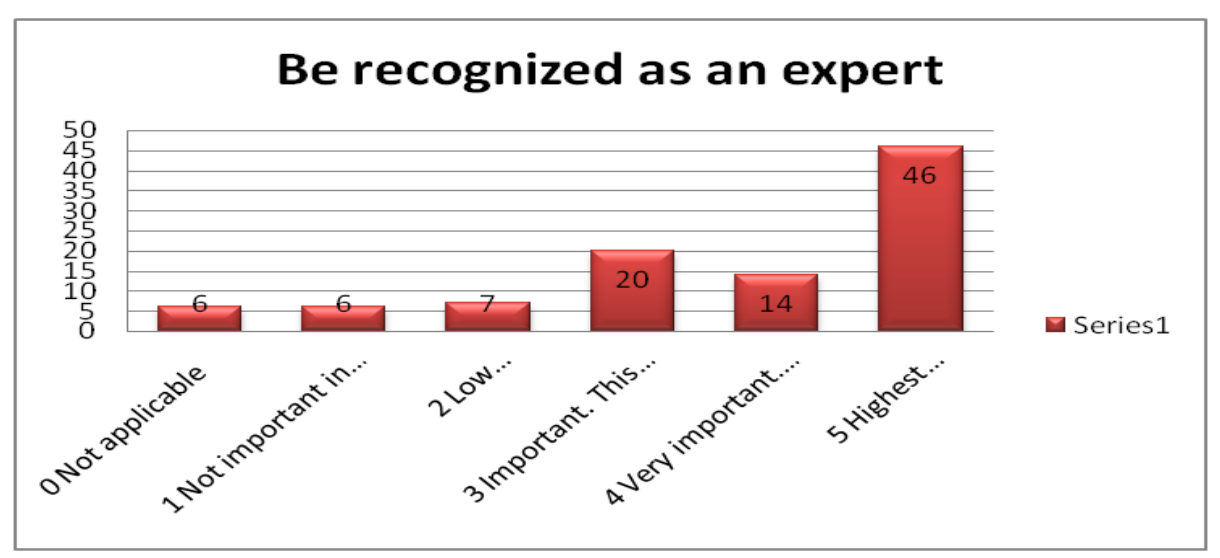




\section{RECOMMENDATIONS}

\section{Strategy}

A program strategy is required in order to properly deliver programs to the client community that will aid in developing value. The strategy must consider the needs of the community based on the types of business and organizational activities in the region. A region heavy in manufacturing will have different needs from a region that is primarily involved in financial services. Many of the more general needs, such as leadership and management may be universal, but the focus and delivery of these programs may have to be tailored to the needs of the community.

In the areas of skills in the EPE definition are programs for managers, executives and professionals. These may be courses targeted towards officers and managers in business corporations, not-for-profit organizations and government bodies. Also included in this definition are professionals operating in the high-skills arena, requiring advanced education and, in most cases, professional certification. This group includes such professions as lawyer, accountant, physician and educator. In most cases activity in these professions requires continuing education relative to the profession, but may include business and management education. To advance in careers by moving into management or moving up in the hierarchy two types of programs are required: functional area programs and soft skills programs.

Functional skills programs are those which are primarily concerned with knowledge rather than skills. These may cover functional areas that are typically covered in a Master of Business Administration (MBA) or other management program such as Master of Public Administration (MPA) or Master of Science program in specialized business topics such as finance or marketing.

Another group of programs that fall predominantly into the functional classification are programs that lead to, or are required for, various certifications. These programs are special because the content and outcomes are generally dictated by a national or international body that awards the certification. As discussed elsewhere in this paper, these programs are becoming sought after.

\section{Recommendations for further research}

In the course of this study several topics that were covered are in need of further research. We recommend further research in the following areas:

1. The sample population can be expanded or changed.

2. Utilizing variables included in the HIEEE questionnaire, an analysis can be conducted into the differences in responses based on gender, age group, position in the organization and education completed.

3. A study could be conducted on reasons participants take part in programs that lead to recognized certifications versus those that do not lead to certification.

4. Further research could be conducted into the leadership of EPE programs. This study could look more deeply into the type of leadership that produces the most successful EPE departments.

\section{AUTHOR INFORMATION}

Dr. Vincent S. Daniels (Vince) is Executive Director, Executive Education at the H. Wayne Huizenga School of Business and Entrepreneurship at Nova Southeastern University. He teaches in entrepreneurship, sales management and negotiating, and delivers training to corporations in sales and management. In 1973, Vince Graduated with honors from the University of Tampa. Armed with a BS in Economics, he attended the Thunderbird, American Graduate School of International Management and received an MBA in International Management in 1974, as the Barton Kyle Yount honor graduate. He was also honored as Entrepreneur of the Year in 1988 by Thunderbird. Vince has been listed in Who's Who in the World and Who's Who in the Southeast. He was the founding director of the International MBA program at Florida International University. He taught classes in entrepreneurship, marketing and sales. In 2004 he joined Nova Southeastern University as Executive Director of Executive 
Education. Vince is the author of many articles on sales and strategy, and one book, International Sales - How to Excel in Global Selling.

Robert C. Preziosi was named "Faculty Member of the Year in 2003". He is a professor of management with the Wayne Huizenga Graduate School of Business and Entrepreneurship at Nova Southeastern University. He is faculty chair of HRM and developed the school's Master's Degree in Leadership. He was the recipient of the school's first Excellence in Teaching Award. In December 2000 he was named Professor of the Decade. In 2007 he received the Excellence in Teaching Award from the Hudson Institute. He as a B.A. degree in social science and a M.Ed. degree in learning psychology. He received his doctoral degree in management. He has a special certification in coaching skills, participative leadership, and consulting skills, and has completed study at Harvard University's Institute for the Management of Lifelong Education. He is listed in Who's Who in Finance and Industry, Who's Who in the World, and Who's Who in American Education. Four times he has been selected for Who's Who Among America's Teachers. In a recent book, North American Adult Educators, he was named 1 of 50 quintessential adult educators of the $21^{\text {st }}$ century. He is on the editorial board of four journals.

Bob has been a national seminar leader for the American Management Association and Dun \& Bradstreet. He has presented to regional, national, and international conferences on various aspects of leadership, management, and adult learning. Bob has recorded two videos, "The High Performing Trainer" and "The High Performance Team". He has a six-part audio program titled, "Executive Success Strategies," in addition to his six-part audio series on "Maximizing Adult Learning". He is the Editor of the Pfeiffer Annual on HRM and a new Annual on Management Development. Bob has just completed a book on leadership, The Leadership Zone.

\section{REFERENCES}

1. Anell, B. \& Wilson, T. (2002). Prescripts: Creating Competitive advantage in the knowledge economy. Competitive Review, 12(1), 26-37.

2. Berg, L. (1998). Qualitative research methods for the social sciences, Allyn \& Bacon

3. Brown, R.H. (2002). Overcoming Educational Exclusion. The American Behavioral Scientist, 45(7), 1061. Retrieved September 15, 2005, from ABI/INFORM Global database.

4. $\quad$ Burton-Jones, A. (1999). Knowledge Capitalism. Oxford University Press.

5. Chauvel, D. \& Despres, C. (2000). A thematic analysis of the thinking in knowledge management. Boston: Butterworth-Heinemann.

6. Crotty, P.T., \& Soule, A.J. (1997). Executive education: yesterday and today, with a look at tomorrow. Journal of Management Development, 16(1). 4-21.

7. Drucker, P. F. (1994). The Age of Social Transformation. The Atlantic Monthly, November, 1994.

8. Drucker, P. F. (1999). Beyond the Information Revolution. The Atlantic Monthly, October, 1999.

9. $\quad$ Edvinsson, L, Sullivan, P (1996), "Developing model for managing intellectual capital", European Management Journal, , Vol. 14 No.4.

10. Garnett, J.. (2001). Work based learning and the intellectual capital of universities and employers. The Learning Organization, 8(2), 78-81.

11. Gore, A. (1999). $21^{\text {st }}$ Century Skills for $21^{\text {st }}$ Century Jobs, speech given at Vice President's summit, January 12, 1999

12. Grant, M. (1994). The Ancient Historians. New York: Barnes \& Noble.

13. Hussey, J., Hussey, R., (1997). Business Research: A Practical Guide for Undergraduate and Postgraduate Students. Palgrave.

14. Kerka, S. (1993). Career Education for a Global Economy. Clearinghouse on Adult Career and Vocational Education.

15. Klein, D.A. (1998). The strategic management of intellectual capital. Boston: Butterworth-Heinemann, 1.

16. Lee, W., Jones, P., Mineyana, Y. \& Zhang, X (2002), Cultural differences in responses to a likert scale, Research in Nursing and Health, 25(4) pp 295-306.

17. Maurer, J. \& Pierce, H. (1998) A comparison of Likert scale and traditional measures of self-efficacy, Journal of applied psychology, 83(2), pp 324-329

18. Moon, Y. \& Kym, H. (2006). A Model for the Value of Intellectual Capital. Canadian Journal of Administrative Sciences, 23(3), 253-269. 
19. Nonaka, I. \& Takeuchi, H. (1995). The Knowledge-Creating Company. Oxford University Press.

20. Nonaka, I. "A Dynamic Theory of Organizational Knowledge Creation," Organization Science (5:1), Feb 1994, pp 14-37.

21. Nyman, M. (2006). Want to Be a Topflight Leader? Hone Your People-skills. Chemical Engineering, 113(8), 63-65.

22. Ok, W. \& Tergeist, P. (2002). Supporting Economic Growth Through Continuous Education and Training-Some Preliminary Results. Meeting of National Economic Research Organisations.

23. Organization for Economic Co-Operation and Development (OECD). (1996). The Knowledge-Based Economy. Organization for Economic Co-operation and Development. Paris.

24. OECD. (1999a). Education: New Economy, New Challenges? OECD Highlights (19).

25. OECD. (1999b). Measuring Knowledge in Learning Economies and Societies. Draft report on Washington Forum. Organisation for Economic Cooperation and Development.

26. Rea, L \& Parker, R. (1997). Designing and Conducting Survey Research, Jossey-Bass

27. Singh, R. (2005). The Missing "Soft Skills" for Project Controls. AACE International Transactions,DE11DE12.

28. Sizer, J., Research and the Knowledge Age. (2001). Tertiary Education and Management, 7(3), 227.

29. Stewart, T. (1997), Intellectual Capital: The New Wealth of Nations, Nicholas Brealy, London

30. Wood, J. (2003). Australia: An Under Performing Knowledge Nation? Journal of Intellectual Capital, 4(2), 144.

31. Yin, R. (1994). Case study research: design and methods. Sage Publications, Inc. 